\title{
Demand for Supplementary Health Insurance in Switzerland : A Theoretical and Empirical Investigation *
}

\author{
by Peter Zweifel **
}

\section{Introduction}

In the health care sector of countries where individuals basically decide themselves about the amount of health insurance, there are signs of a cost-insurance spiral. It consists of two dynamic relationships. Let the insurer initially offer a policy with reduced cost-sharing by the insured. This may be a government-mandated change or a means to gain a short-term edge in the competition among insurers. Due to increased coverage, demand for services increases, from the probability of an initial physician contact on to the continuation of ambulatory treatment and to the propensity of hospitalization (Newhouse and Phelps [1976] ; Manning et al [1981] ; see Cairns and Snell [1978] for a survey). The demand increase exerts an upward pressure on fees charged by service providers (Sloan [1976] ; Steinwald and Sloan [1974]). It is the adjustment of the insured to this change which constitutes the second link of the cost-insurance spiral. If the insured shy away from the increased financial risk associated with a sickness episode, they will opt for increased coverage. The crucial point is whether they tend to overshoot even in the longer run. If they do, they are less likely to restrain demand than before, being even more sheltered from the actual price of medical care. The spiral may go into its next turn.

In a pioneering study, Feldstein [1973] combined empirical estimates of demand for health insurance with estimates of demand for hospital care, given insurance. Conditional upon the auxiliary hypothesis of a geometric lag structure, he found a stable dynamic relationship. Much of the dynamics of the process seems to be due to the growth of the health insurance market per se. In Switzerland however, the

* This is a thoroughly revised version of a paper presented to the Eighth Seminar of the European Group of Insurance Economists in Cologne, September 23 to 25, 1981. The author would like to thank Karl Borch, Roland Eisen, Jörg Finsinger, Alberto Holly, and Henri Loubergé for helpful comments and criticisms. Financial support by the Swiss National Science Foundation under Grant No. 4.349-079.08 of the National Research Program No. 8 is gratefully acknowledged.

** Institute for Empirical Economic Research, University of Zurich. 
overwhelming majority of the population has been covered by social health insurance for a long time; yet the same dynamic relationship seems to manifest itself. This paper is concerned with the demand for supplementary hospital insurance for semiprivate or private accommodation in a period of rapidly rising costs of health care. After a short survey of research into the economic theory of insurance and of health insurance in particular, a model of demand for supplementary hospital insurance under bounded rationality is developed. Section 4 is devoted to the derivation and interpretation of the necessary conditions for an optimum. The comparative static implications of a price increase of medical care are worked out in section 5. The following section deals with the second-order effects that may arise because of the sick fund's policy to encourage adjustments of coverage by special offers. In particular, such special offers are predicted to aggravate the problem of adverse risk selection. This hypothesis is empirically tested using some 1600 individual observations over the years 1976-1980, thus avoiding the problems of aggregation in Feldstein's [1973] work. This data base is described in section 7. The econometric results are presented in section 8 along with a preliminary evaluation of special offers and their effects on risk selection. Section 9 contains the main conclusions.

\section{A short review of previous research into the economics of health insurance}

The economic theory of insurance is a new discipline, initiated by Arrow's [1965, 1970] and Pratt's [1964] analysis of decisions under risk. They introduced the concept of risk aversion and demonstrated its relationship to the premium a risk-averse individual is prepared to pay in order to avoid risk ; for an empirical estimate of risk aversion, see Friedman [1974]. Mossin [1968] showed that a utility-maximizing individual will purchase full coverage only if the insurance offer is actuarially more than fair. This result is rather puzzling in view of the common observation that individuals as a rule do not care to mitigate risks, but to eliminate some of them entirely. Moreover, the existence of a cost-insurance spiral converging to full coverage would have to be linked with the terms of insurance becoming more and more favorable to the insured. The notion that an insurance budget has to be allocated over many risks has been put forward by Ehrlich and Becker [1972]. In their model, contingent claims are very similar to usual economic goods. The only difference to the theory of consumer demand lies in the difficulty that the price of insurance is not observed like ordinary market prices of goods. Rather, it is given by an implicit trade-off between certain wealth and the size of the contingent claim if a loss occurs. For all its elegance, the Ehrlich-Becker formulation is not very useful in the analysis of health insurance. First, only a few states are distinguished in the typical contract. Second, payment is not conditional upon the loss of health itself, which is nonmonetary, but rather upon the inputs used in the effort to recoup the loss. Third, payment is not only affected by the decisions of the insured but mainly by the decisions of a largely independent agent, the physician. Fourth, health insurance is also closely connected to sick-leave and hence may be expected to affect labor supply in a much more direct manner than other branches of insurance. The first two points have been taken into account by Phelps [1973, 1976], whereas aspects related to physician behavior and labor supply will be also considered in the model to be presented below. 
Other, more fundamental problems will not be addressed here, although they may well be at the root of present concerns about health insurance and its financial equilibrium. They relate to the existence of a stable Pareto-optimal equilibrium in the market. At the heart of the problem is the incompatibility of risk spreading and the incentive to contain costs (Zeckhauser [1970]). Introducing the ex ante - ex post distinction, Starr [1973] has shown that individuals must have identical expectations about probabilities of states for a static equilibrium to be Pareto-optimal ex post as well as ex ante. Moreover, production uncertainty cannot be ruled out in the context of health insurance. If relative productivities of inputs used by agents (e.g. own time and medical care) depend on the state of nature in effect, the feasibility set in terms of health status and net disposable income or consumption may become nonconvex, cf. Arrow ([1970], pp. 131-133). Finally, an equilibrium may fail to exist due to the information asymmetry between insurer and insured. Given the substantial costs of discriminating between good and bad risks, the insurer will resort to offering one common policy to all potential demanders as a second-best solution. This policy is likely to be suboptimal for bad and/or good risks (Rothschild and Stiglitz [1976] ; Eisen [1979], pp. 114-118). Whether a dynamic equilibrium exists when insurers drive out good risks by increasing their premium in response to moral hazard must be regarded as an unsettled question.

\section{A model of insurance demand assuming bounded rationality}

In this section a model of the demand for health insurance coverage is sketched, which incorporates the assumption of bounded rationality of the insured on the one hand and some peculiarities of policies written by typical European sick funds on the other hand. The individual is rational in a restricted sense only because he does not consider ex ante the relationship between his choice of coverage now and the fact that he will incur higher expected costs in the future due to his own behavior and because he considers his medical bill to be a random variable as soon as his physician refers him to a hospital.1

Both assumptions deviate from the received literature on the demand for health insurance, represented e.g. by Phelps [1976]. But they may well mirror the subjective decision situation of an individual who is already highly insured compared to American standards and who has therefore been encouraged to fully delegate decisions to the physician in charge. Moreover, given the extensive coverage of income loss due to sickness, becoming ill may have become a way of avoiding the pressures of work.

1 Regarding the hospital bill as a random variable is not meant to deny that patients as a group influence physician behavior. In fact, Steinwald and Sloan [1974] find statistically significant relationships between the share of high income and high age patients on the one hand and the average fee charged by physicians in general practice on the other. Sloan and Lorant [1977] successfully introduce similar variables (along with physician-related ones, of course) in their study of waiting time for a visit. The critical symptom level $(c)$, a latent decision variable governing referral and hospitalization, is found to be related to average symptom intensity $(\bar{s})$ and average patient income in the work of Zweifel ([1982 a], ch. 9). 
This notion is introduced into the model by postulating that the individual is interested in times of good health available for leisure, but not for work. The objective function then reads

$$
\begin{aligned}
E(U) & =\int_{0}^{c} U[Y(s), H(s)] f(s, \bar{s}) d s+\int_{c}^{m} U[Y(s), H(s)] f(s, \bar{s}) d s \\
& +\int_{m}^{1} U[Y(s), H(s)] f(s, \bar{s}) d s \rightarrow \text { max. }
\end{aligned}
$$

$c$ : Critical symptom level, where the private physician proposes hospitalisation;

$E$ : Expectation operator, defined over $(s)$;

$f$ : Density function of symptom level $(s)$;

$H$ : Number of healthy days, net of days worked ;

$m$ : Emergency symptom level where the individual is immediately hospitalized;

$s$ : Symptom level, random variable, $0 \leqslant s \leqslant 1$;

$\bar{s}$ : Parameter characterizing the density function $f(\cdot)$ of $(s)$, e.g. mean symptom intensity ;

$U$ : Utility function, defined over $(Y, H)$;

$Y$ : Wage income net of insurance premium and outlays for medical treatment.

Clearly, three states of nature are distinguished. In the first, the individual is basically healthy. He works and can be treated within the ambulatory sector. This state is characterized by a symptom intensity level $(s)$ varying between zero and a critical level $(c)$ where the physician would admit the individual to a hospital. In the second state, the symptom intensity lies between $(c)$ and an emergency threshold $(m)$. This means that the individual has time to search for a hospital in which the daily room charge is covered by his policy. Unless he has settled for the public ward, he runs a certain risk of treatment costs exceeding the limits specified in his policy. In the third state, $(s)$ exceeds even $(m)$; the insured is brought to the nearest hospital as an emergency. That hospital may turn out to charge a daily room rate far above the limit covered by the policy.

The restrictions complementing the maximization problem (1) vary according to the three states. In the first, we have

$$
\left.\begin{array}{l}
Y=w[W-g \cdot t \cdot M]-r \cdot q \cdot M-R \\
H=T-L(M, s)-W
\end{array}\right\} 0 \leqslant s<c(M)
$$

$g$ : Share of working time lost due to ambulatory care which is deducted in the calculation of wage income ;

$L:$ Time lost due to sickness, in days (derived decision variable);

$M$ : Duration of ambulatory treatment, in fractionals of physician days (decision variable);

$q$ : Implicit physician wage rate, per physician day ;

$R$ : Premium paid to the sick fund (derived decision variable, see below);

$r$ : Coinsurance rate applied to ambulatory care ;

$s:$ Symptom intensity; 
$T:$ Total time;

$t$ : Time input of individual, per day of ambulatory care;

$W$ : Working time, in days (decision variable);

$w$ : Wage rate of the individual, per working day.

Remaining symbols see eq. (1).

Gross labor income is given by the product of wage rate $(w)$ times working time $(W)$. If the individual is actually paid by the hour, he suffers an income loss when seeing the ambulatory care physician $(0<g \leqslant 1)^{2}$ In contrast, most public employees may take time off for health reasons while still receiving their full income $(g=0)$. Both types of individuals share in the cost of ambulatory care at the tune or $(r)$ which is exogenously fixed at 10 percent $(r=0.1) .^{3}$ This cost is split into a price and a quantity component. The service price $(q)$ is unobserved because physicians are remunerated according to a fee schedule. Since seeing a physician may be interpreted as a decision about the division of labor in the production of health, the patient is assumed to buy physician time. However, the physician is free to vary the time content and combination of procedures. Hence, $(q)$ rises not only when physicians negotiate fee increases from sick funds but also when they bill more time-saving procedures (such as X-ray work) or dispense more drugs (Zweifel [1981]). The quantitative component $(M)$ is interpreted as the individual's demand for physician time, given $(s)$. The higher $(M)$, the more a physician recognizes the pressure of demand exerted on him. In order to ease his work burden, he will tend to lower his critical symptom level (c) ; for empirical evidence to this effect, see Zweifel [1982 a]. For the insured individual, a high demand for ambulatory care increases the probability of hospitalization. Therefore, the critical symptom level $(c)$ is - albeit to a very limited degree influenced by the individual himself. ${ }^{4}$ Finally, premium payments $(R)$ are introduced

2 It is assumed that ambulatory care always takes place during working time. Leisure time sacrificed for seeing a physician would have to be valued at the individual's wage rate as well, following Becker [1965]. Moreover, active and non-active members of the Krankenkasse KKB, a major Swiss sick fund, were asked to supply their own, subjective estimate of their marginal value of time. Although formulated for a fully active individual, the model may therefore be applicable to the entire adult population.

3 It is very difficult to determine the ex ante relevant rate of coinsurance for an individual insured by a Swiss sick fund. Under general membership (rather than semiprivate or private), he contributes a deductible of 30 francs per quarter of ambulatory care, or $10 \%$ of the bill, whichever is greater. This means that the marginal coinsurance rate is $100 \%$ in the interval $[0,30], 0 \%$ in the interval $(30,300]$, and $10 \%$ above $300 \mathrm{sFr}$. The expected coinsurance rate therefore depends on the severity of the illness, symbolized by the symptom level (s). For further details, cf. Zweifel ([1982 a], ch. 7).

4 If the critical symptom level $(c)$ were independent of the demand for ambulatory care $(M)$, then $(M)$ would be entirely disconnected from hospital insurance. Such an implication is contrary to empirical evidence, at least in the case of the U.S. : Newhouse and Phelps [1976] found that $(M)$ was negatively related to the hospital coinsurance rate, with an elasticity of -.07 (with asymptotic $Z$ statistic of 3.94). This effect should be attenuated under conditions typical for Europe because full transfer of control from the private to the hospitalbased physician is much more frequent than in the U.S. 
as another deduction of gross income; they are related to the amount of insurance chosen, cf. eq. (8) below. The tax on income is disregarded for the time being. ${ }^{5}$

Turning to the time restriction in eq. (3), we see that ambulatory care not only costs time, but saves some as well. Out of a total of days $(T)$, an amount $L$ is lost due to sickness. Ambulatory care $(M)$ reduces that loss for all symptom levels below (c). The further deduction of working days $(W)$ mirrors the assumption that the individual regards work as a must; he is interested in it only as a means for earning an income. Time spent on ambulatory care does not enter the expression because it is part of gross working time by assumption.

The second state, in which the individual is referred to a hospital but does not find himself under pressure to find a bed immediately, is characterized by the restrictions

$$
\left.\begin{array}{l}
Y=\bar{Y}-[q \cdot K(s)-X]-R \\
H=T-L[K(X, s), M(s)]
\end{array}\right\} c \leqslant s<m
$$

$X$ : Upper limit ot treatment costs covered by the policy (decision variable);

$\bar{Y}$ : Transferred income in case of hospitalization.

Remaining symbols see eqs. (1) to (3).

Since the individual cannot work when in the hospital, he receives an income transfer $(\bar{Y})$ instead of his earned wage income $(Y)$. Swiss law traditionally requires sick funds to offer a minimum daily transfer payment as part of their health insurance package. This part of the policy is very rarely modified; therefore, it is not expected to contribute to the dynamics of the cost-insurance spiral and will not be analyzed as a separate decision variable. Out of his transferred income the individual must cover any difference between the treatment costs incurred in the hospital, given by $q \cdot K(s)$, and the insured upper limit, $(X)$. Board and room charges leave his net income unaffected because in state 2 he is able to select a hospital whose rate is fully covered by his insurance policy. Since working time $(W)$ is zero in the advent of hospitalization, net healthy time is solely determined by the loss $(L)$. According to eq. (5), this loss basically depends on the severity of the condition ( $s$ ) but also on the intensity of treatment $(K)$, which is under the physician's control. The physician, while acting in response to $(s)$, may well choose a more intensive therapy when insurance coverage $(X)$ is generous.

The third state of nature is very similar to the second one.

$$
\left.\begin{array}{l}
Y=\bar{Y}-(q-b) \cdot M(s)-[q \cdot K(s)-X]-R \\
H=T-L[K(s), M(s)]
\end{array}\right\} m \leqslant s \leqslant 1
$$

5 Payments for health and life insurance as well as interest on saving accounts may be deducted from taxable income under Swiss federal law as well as some member state laws. Taken together, these items must not exceed a limit that amounts to 5-7\% of average gross income, however. Most of the allowance will be exhausted by life insurance premiums and interest on savings accounts. Tax exemption is therefore unlikely to contribute much to the dynamics of the cost-insurance spiral. 
$b:$ Upper limit of daily room rate covered by the policy (decision variable);

$M$ : Length of stay in the hospital, in days (remaining symbols explained above).

There are two differences, however. First, net income is further reduced. For in the case of sudden, major illnesses and accidents in particular, the individual cannot influence the choice of the hospital anymore. He may therefore find himself in an institution whose daily room charge will be only partially covered by his policy. This means that the difference $(q-b)$ will be his daily out-of-pocket expense, for a period of $(M)$ days. Second, the loss of healthy days is totally unaffected by insurance coverage : In the case of an emergency, physicians are thought to choose treatment according to $(s)$ only.

The three states are bound together by a restriction that must hold at least on average if a sick fund is to maintain its financial equilibrium. Since the funds are non-profit organizations, it may be not entirely unrealistic to posit that the premium $(R)$ paid by an individual member is equal to the expected value of costs attributable to him. This is the pricing principle associated with the notion of actuarially fair insurance; for other pricing rules which take individual risk aversion into account, see Borch [1974] ; for different interpretations of equivalence in insurance, see Eisen [1979]. Basically, we have for each member of the fund

$$
\begin{aligned}
R=(1+\theta) & {\left[\int_{0}^{c}(1-r)[q \cdot M\rceil f(s, s) d s+\int_{c}^{m}[q \cdot M(s)+q \cdot K(X, s)] f(s, s) d s\right.} \\
& \left.+\int_{m}^{1}[b \cdot M(s)+X] f(s, \bar{s}) d s\right]
\end{aligned}
$$

$\theta$ : Loading factor for covering administration costs and accumulation of reserves.

(Remaining symbols explained above).

In the next section we focus on a change $(d q)$ and its effects on the demand for insurance, while section 5 will be devoted to the second-order effects of a concomitant variation $(d \theta)$ of the loading factor.

\section{Necessary conditions for optimal coverage}

In this section, we study the choice of supplementary hospital insurance coverage of a typical individual on the assumption that eqs. (1) to (8) adequately depict his decision situation. Working time $(W)$ and demand for ambulatory care in state $1(M)$ are taken to be predetermined. Demand for insurance has the dimensions $(b)$ and $(X)$, representing the upper limit on treatment costs. Contrary to private health insurance, the rate of coinsurance $(r)$ is fixed by law and therefore exogenous. ${ }^{6}$ At an interior optimum, we have, using $E U$ as a shorthand for $E(U)$,

6 Private health insurers in Switzerland are free to offer policies with variable coinsurance rates and deductibles. However, they mostly write policies with no coinsurance and deductibles of no more than $500 \mathrm{sFr}$. per year (some 275 US dollars at 1980 exchange rates). Swiss social insurance law specifies an upper limit of $10 \%$ for cost-sharing in ambulatory care. This limit is applied throughout by sick funds. 
(9)

$$
\frac{\partial E U}{\partial b}=0, \frac{\partial E U}{\partial X}=0 ;\left[\begin{array}{ll}
\frac{\partial^{2} E U}{\partial b^{2}} & \frac{\partial^{2} E U}{\partial b \partial X} \\
\frac{\partial^{2} E U}{\partial b \partial X} & \frac{\partial^{2} E U}{\partial X^{2}}
\end{array}\right] \text { negative definite. }
$$

Using eqs. (1) to (8), we obtain for the first necessary condition

$$
\begin{aligned}
\frac{\partial E U}{\partial b}= & \frac{\partial}{\partial b}\left[\int_{0}^{c} U(\cdot) f(\cdot) d s+\int_{c}^{m} U(\cdot) f(\cdot) d s+\int_{m}^{1} U(\cdot) f(\cdot) d s\right] \\
= & \int_{0}^{c} \frac{\partial}{\partial Y}[U(\cdot)] \frac{\partial Y}{\partial b} f(\cdot) d s+\int_{c}^{m} \frac{\partial}{\partial Y}[U(\cdot)] \frac{\partial Y}{\partial b} f(\cdot) d s+\int_{m} \frac{\partial}{\partial Y}[U(\cdot)] \frac{\partial Y}{\partial b} f(\cdot) d s \\
& +\int_{0}^{c} 0 \cdot f(\cdot) d s+\int_{c}^{m} 0 \cdot f(\cdot) d s+\int_{m}^{1} 0 \cdot f(\cdot) d s \\
= & 0 .
\end{aligned}
$$

The three vanishing terms at the end of the equation mirror the fact that varying (b) has no influence on the number of healthy days $(H)$. For in state $1(0<s<c)$, there is no relationship whatsoever between $(H)$ and $(b)$, cf. eq. (3). In states 2 and 3 $(c \leqslant s \leqslant 1)$, the number of healthy days is determined by the symptom level $(s)$ and therefore a random variable independent of $(b)$, cf. eqs. (5) and (7). We now turn to the partial relationship between net income $(Y)$ and the insured daily room rate $(b)$. Again, the three states are distinguished by the individual as well as by the sick fund (cf. eq. (8)) :

$$
\frac{\partial Y}{\partial b}= \begin{cases}-\frac{\partial R}{\partial b}=-(1+\theta) \int_{m}^{1} M(s) f(\cdot) \mathrm{ds}<0 & 0 \leqslant s<c \\ -\frac{\partial R}{\partial b}=-(1+\theta) \int_{m}^{1} M(s) f(\cdot) \mathrm{ds}<0 & c \leqslant s<m \\ M(s)-\frac{\partial R}{\partial b}=M(s)-(1+\theta) \int_{m}^{1} M(s) f(\cdot) \mathrm{ds}>0 & m \leqslant s \leqslant 1\end{cases}
$$

The sign of the third expression of eq. (11) is based upon an assumption. The expression basically shows how individual expectations concerning an emergency differ from the evaluation by the sick fund. We assume that state 3 is like a catastrophe for the typical individual ; i.e. the values of $M(s)$ are skewed towards the natural upper bound of 365 days per year. In contrast, the sick fund has rather precise estimates of $(\bar{s})$, of the density of $(s)$ given $(\bar{s})$ in the interval $(m, 1)$ and of the length of stay $M(s)$ associated with it. It knows in particular that a good deal of emergency admissions turn out to be for rather minor conditions. Under this assumption, we have

$$
M(s)-\int_{m}^{1} M(s) f(\cdot) \mathrm{d} s>0
$$

$m \leqslant s \leqslant 1$ 
Taken together, eqs. (10) and (11) yield

$$
\begin{aligned}
\frac{\partial E U}{\partial b}= & \int_{0}^{c}\left[-U_{y}(1+\theta) E M\right] f(\cdot) d s+\int_{c}^{m}\left[-U_{\gamma}(1+\theta) E M\right] f(\cdot) d s \\
& +\int_{m}^{1} U_{\gamma}[M(s)-(1+\theta) E M] f(\cdot) d s=0 . \\
(+) &
\end{aligned}
$$

$U_{Y}$ : Marginal utility of income, $=\partial U / \partial Y$;

$E M$ : Expectations of $M(s)$ as estimated by the sick fund,

$$
=\int_{m}^{i} M(s) f(s, \bar{s}) d s .
$$

When selecting his preferred coverage of the daily room rate $(b)$, the individual must therefore weigh three aspects against each other. As long as he is basically healthy or at least has some liberty in planning his admission to the hospital (states 1 and 2), he loses income by opting for a higher $(b)$. In the optimum, this expected loss is matched by the avoided loss of income due to insufficient insurance coverage in the emergency state 3. It is remarkable that the restriction (12), together with the requirement that $(\theta)$ be small, is sufficient for the existence of an optimum with $b>0$. In similar manner, the first-order optimum conditions with regard to maximum treatment costs covered by the policy is

$$
\begin{aligned}
\frac{\partial E U}{\partial X}= & \int_{0}^{c} \frac{\partial}{\partial Y}[U(\cdot)] \frac{\partial Y}{\partial X} f(\cdot) d s+\int_{c}^{m} \frac{\partial}{\partial Y}[U(\cdot)] \frac{\partial Y}{\partial X} f(\cdot) d s \\
& +\int_{m}^{1} \frac{\partial}{\partial Y}[U(\cdot)] \frac{\partial Y}{\partial X} f(\cdot) d s \\
& +\int_{0}^{c} 0 \cdot f(\cdot) d s+\int_{c}^{m} \frac{\partial}{\partial H}[U(\cdot)] \frac{\partial H}{\partial X} f(\cdot) d s+\int_{m}^{1} 0 \cdot f(\cdot) d s \\
& =0 .
\end{aligned}
$$

The effect of a change of $(X)$ on net income, $\partial Y / \partial X$, is again state-dependent, due to eqs. (3), (5) and (7) :

$$
\frac{\partial Y}{\partial X}= \begin{cases}-\frac{\partial R}{\partial X}=-(1+\theta) \int_{m}^{1} f(\cdot) \mathrm{d} s<0 & 0 \leqslant s<c \\ 1-\frac{\partial R}{\partial X}=1-(1+\theta) \int_{m}^{1} f(\cdot) \mathrm{d} s>0 & c \leqslant s<m \\ 1-\frac{\partial R}{\partial X}=1-(1+\theta) \int_{m}^{1} f(\cdot) \mathrm{d} s>0 & m \leqslant s \leqslant 1\end{cases}
$$

For state 2, eq. (15) should, in view of eq. (8), contain a term in $\partial K / \partial X$, mirroring the sick fund's anticipation of increased treatment intensity in response to higher insurance coverage. There are no indications to the effect that premium functions are adjusted accordingly, however. Rather, the claim distribution is still taken as given 
and independent of the extent of insurance coverage, cf. Schmid [1978] and fn. 11. With the small values of $(\theta)$ noted above, the sign restrictions are self-evident. ${ }^{7}$

In contradistinction to the other states, there is an indirect influence of $(X)$ on the number of healthy days in the second state, amounting to

$$
\frac{\partial H}{\partial X}=\frac{\partial L(\cdot, s)}{\partial K} \cdot \frac{\partial K}{\partial X}
$$

Substituting eqs. (15) and (16) into eq. (14), we obtain

$$
\begin{aligned}
& \frac{\partial E U}{\partial b}=\int_{0}^{c}\left[-U_{\gamma}(1+\theta) F\right] f(\cdot) d s+\int_{c}^{m}\left[-U_{Y}\{1-(1+\theta) F\}\right] f(\cdot) d s+\int_{c}^{m}\left[-U_{H} \frac{\partial L}{\partial K} \cdot \frac{\partial K}{\partial X}\right] f(\cdot) d s \\
& +\int_{m}^{1}\left[U_{Y}\{1-(1+\theta) F\}\right] f(\cdot) d s \\
& =0.8
\end{aligned}
$$

$F$ : Probability of $(s)$ exceeding the emergency level $(m)$,

$$
=\int_{m}^{1} f(s, \bar{s}) d s \text {. }
$$

This condition is easy to interpret. The income loss due to the additional premium payable for a marginal increase in $(X)$ must be balanced against two advantages. The first is the assurance that the hospital physician will be less constrained by cost in his choice of treatment. Although only relevant in state 2, this may carry a great weight in terms of marginal utility. The other advantage is the decreased risk of out-of-pocket expenditures in states 2 and 3 , where costs of stationary treatment may exceed the limit $(X)$. The location of the optimum depends on the premium schedule of the sick fund which defines the marginal cost of insurance. It also depends on the characteristics of the insured. If he thinks of his personal distribution of symptom levels as being skewed toward low values, he will select a low value of $(X)$. Another subjective component is the marginal utility of income $\left(U_{Y}\right)$ in the three states, about which no generally valid statement seems possible. For on the one hand, a sick person cannot enjoy additional income very much for consumption purposes. This would make for comparatively low values of $U_{Y}$ in states 2 and 3 . On the other hand, a major illness may still result in economic distress for many so that additional net income would be of particular benefit. Individuals emphasizing this aspect will opt for rather extensive health insurance.

\section{The effects of rising health care costs on the demand for insurance}

We now turn to the question of how an individual portrayed by eqs. (1) to (8) will react to changes in his environment. One such important change has been the general

7 Administrative costs and reserve accumulation together amount to $9.5 \%$ of total accounting outlays of the Krankenkasse KKB in 1979, with little variation since 1976. This estimate of average $\theta(0.095 / 1-0.095)=0.105)$ may conceal variations among different branches, membership classes (general, semiprivate, private), and age-region segments.

8 Marginal utilities $\left(U_{Y}, U_{H}\right)$ may well differ between states 1,2 , and 3 . However, this variation is not made explicit in the text for the sake of simplified notation. 
increase of fees in the health care sector (see section 7). Let now the optimum solution be disturbed by the shock $(d q)$. If the individual is to balance this disturbance by adjusting his decision variables $(b)$ and $(X)$, with demand for ambulatory care $(M)$ and working time $(W)$ fixed, we must have

$$
\begin{aligned}
& \frac{\partial}{\partial b}\left[\frac{\partial}{\partial b} E U\right] d b+\frac{\partial}{\partial X}\left[\frac{\partial}{\partial b} E U\right] d X+\frac{\partial}{\partial q}\left[\frac{\partial}{\partial b} E U\right] d q=0 \\
& \frac{\partial}{\partial b}\left[\frac{\partial}{\partial X} E U\right] d b+\frac{\partial}{\partial X}\left[\frac{\partial}{\partial X} E U\right] d X+\frac{\partial}{\partial q}\left[\frac{\partial}{\partial X} E U\right] d q=0 .
\end{aligned}
$$

Using vector notation and marking sign restrictions, we obtain

$$
\left[\begin{array}{cc}
\frac{\partial^{2} E U}{\partial b^{2}} & \frac{\partial^{2} E U}{\partial b \partial X} \\
(-) & (+/-) \\
\frac{\partial^{2} E U}{\partial b \partial X} & \frac{\partial^{2} E U}{\partial X^{2}} \\
(+/-) & (-)
\end{array}\right]\left[\begin{array}{c}
d b \\
(+/-) \\
\frac{\partial^{2} E U}{\partial X \partial q} \\
(+/-)
\end{array}\right] d q .
$$

The diagonal elements of the Hessian are necessarily negative if the conditions specified in eq. (9) are assumed to hold (Chiang [1974] ; pp. 329-331). Restrictions on the remaining elements of the equation system require further elaboration. As an example, we consider the expression $\partial^{2} E U / \partial b \partial q$ appearing in the impulse vector to the right of eq. (18):

$$
\begin{aligned}
\frac{\partial^{2} E U}{\partial b \partial q} & =\frac{\partial}{\partial q} \int_{0}^{c}\left[-U_{Y}(1+\theta) E M\right] f(\cdot) d s \\
& +\frac{\partial}{\partial q} \int_{c}^{m}\left[-U_{Y}(1+\theta) E M\right] f(\cdot) d s \\
& +\frac{\partial}{\partial q} \int_{m}^{1}\left[U_{Y} M(s)-(1+\theta) E M\right] f(\cdot) d s ; \text { cf. eq. (13). }
\end{aligned}
$$

$E M$ : Expected value of $M(s)$ in state 3 as seen by the sick fund,

$$
=\int_{m}^{1} M(s) f(s, s) d s \text {. }
$$

Since length of stay is interpreted as a random variable beyond the individual's control, a change $(d q)$ has no impact on the number of healthy days in state $3 .^{9}$ Its partial influence on net income, on the other hand, is given by

9 This view contrasts in particular with Phelps' [1973, 1976] formulation in which no distinction is made between ambulatory and stationary care. All services, from the initial physician visit to treatment in a high intensity care unit, are aggregated into a common demand variable there. 


$$
\frac{\partial Y}{\partial q}= \begin{cases}-r \cdot M & 0 \leqslant s<c \\ -K(X, s) & c \leqslant s<m \\ -[M(s)+K(s)] & m \leqslant s \leqslant 1\end{cases}
$$

The decision variables $(M)$ and $(W)$ being predetermined at the time the decision about insurance coverage is made, all terms in $(H)$, involving $\left(U_{H H}, U_{Y H}\right)$ can be disregarded in the evaluation of eq. (19), yielding

$$
\begin{aligned}
& \frac{\partial^{2} E U}{\partial b \partial q}=\int_{0}^{c}\left[U_{Y Y} \cdot r M(1+\theta) E M\right] f(\cdot) d s \\
&+\int_{c}^{m}\left[U_{Y Y} \cdot K(X, s)(1+\theta) E M\right] f(\cdot) d s \\
&(-) \\
&+\int_{m}^{1}\left[U_{Y Y}\{M(s)+K(s)\}\{M(s)-(1+\theta) E M\}\right] f(\cdot) d s \\
&(+)
\end{aligned}
$$

$U_{Y Y}$ : Rate of change of marginal utility of income with increasing gain or loss of income, $=\partial^{2} U / \partial Y^{2}<0$,

$$
=-R_{A} / U_{Y}
$$

$R_{A}$ : Coefficient of absolute risk aversion,

$$
=-U_{Y Y} / U_{Y}
$$

The first term of eq. (21) is negative. It can be large, despite the fact that costsharing for ambulatory treatment is limited to $10 \%$ in Switzerland $(r=0.1)$ and that $(M)$, measured in fractionals of physician days, will be small in state 1 . But for most members of the fund, symptom levels in the interval $[0, c)$ will make up for the lion's share of the entire distribution. The second term of eq. (21) is negative as well. The sign of the third term depends on the sign of $\{M(s)-1+\theta) E M\}$. This difference was found to be positive, cf. the optimum condition (13). Since price is defined per day of stay or treatment throughout, the multiplier $[M(s)+K(s)]$ is rather large compared to the patient-controlled $(M)$ of state 1. Both of these bracketed expressions loom large with individuals who subjectively evaluate their health prospect rather pessimistically, or who are particularly risk averse to income variability when they have suffered a severe health loss. ${ }^{10}$ For then, the third term of eq. (21) will tend to outweigh the first two resulting in $\partial^{2} E U / \partial q \partial b>0$. Others, who are confident that they will not need emergency hospitalization, will attribute little weight to the third term of eq. (21) and will thus be characterized by $\partial^{2} E U / \partial q \partial b<0$. Hence, no general sign restriction can be expected to hold with respect to $\partial^{2} E U / \partial q \partial b$, but rather the binary set

10 As noted in fn. 8 above, marginal utilities (and hence coefficients of risk aversion) quite possibly take on different values in states 1,2 , and 3 . The author would like to thank Karl Borch for calling his attention to this point. 


$$
\frac{\partial^{2} E U}{\partial b \partial q}= \begin{cases}<0 & \text { for subjectively good risks, } \\
>0 & \begin{array}{l}
\text { for subjectively bad risks or strong risk averters regarding } \\
\text { state } 3
\end{array}\end{cases}
$$

In a similar vein, we may derive an expression for the second element of the impulse vector on the right-hand side of eq. (18), using eqs. (17) and (20) :

$$
\begin{aligned}
\frac{\partial^{2} E U}{\partial X \partial q} & =\int_{0}^{c}\left[U_{Y Y} \cdot r M(1+\theta)\right] f(\cdot) d s \\
& +\int_{c}^{m}\left[-U_{Y Y} \cdot K(X, s)\{1-(1+\theta) F\}\right] f(\cdot) d s+\int_{c}^{m}\left[U_{Y H} \cdot K(X, s) \cdot \frac{\partial L}{\partial K} \cdot \frac{\partial K}{\partial X}\right] f(\cdot) d s \\
& +\int_{m}^{1}\left[-U_{Y Y}\{M(s)+K(s)\}\{1-(1+\theta) F\}\right] f(\cdot) d s .
\end{aligned}
$$

This expression resembles eq. (21) except for an additional term for state 2, involving the changing marginal utility of income as a function of healthy time $(H)$ and ultimately the severity of illness $(s)$. Intuitively, the marginal utility of income should increase when $H$ approaches the level prevailing in state 1 , when there is no need for stationary treatment. In that event, only the first term of eq. (23) is negative, and we have reason to posit

$$
\frac{\partial^{2} E U}{\partial X \partial q}= \begin{cases}<0 & \text { for subjectively good risks, } \\
>0 & \begin{array}{l}
\text { for subjectively bad risks or strong risk averters regarding } \\
\text { states } 2 \text { and } 3 .
\end{array}\end{cases}
$$

The restrictions (22) and (24) have an intuitive basis. An increase in the price of health services $(d q)$ certainly implies a loss of expected utility on the part of the insured, i.e. $\partial E U / \partial q<0$. A further increase of insurance coverage would only add to this loss for those subjectively healthy individuals who do not want to pay the additional premium for stationary services they do not count on consuming. Hence, we have $\partial^{2} E U / \partial q \partial b<0, \partial^{2} E U / \partial q \partial X<0$ for them. The other members of the fund assign a possibly exaggerated probability to the interval $[c, 1]$ of the symptom density function. By increasing coverage, they can alleviate the loss of expected utility stemming from hospitalization even if they have to pay a higher premium. For them, it may be true that $\partial^{2} E U / \partial q \partial b>0, \partial^{2} E U / \partial q \partial X>0$.

Finally, it can be shown that the interactive impact of the two decision variables upon expected utility should differ according to the subjective evaluation of the individual's health. The restrictions are

$$
\frac{\partial^{2} E U}{\partial b \partial X}= \begin{cases}>0 & \text { for subjectively good risks, } \\
<0 & \begin{array}{l}
\text { for subjectively bad risks or strong risk averters regarding } \\
\text { states } 2 \text { and } 3 .
\end{array}\end{cases}
$$

These preliminaries enable us to place some qualitative restrictions on the solution of the system (18). Applying Cramer's rule and using the inequalities (22), (24) and (25), we obtain 


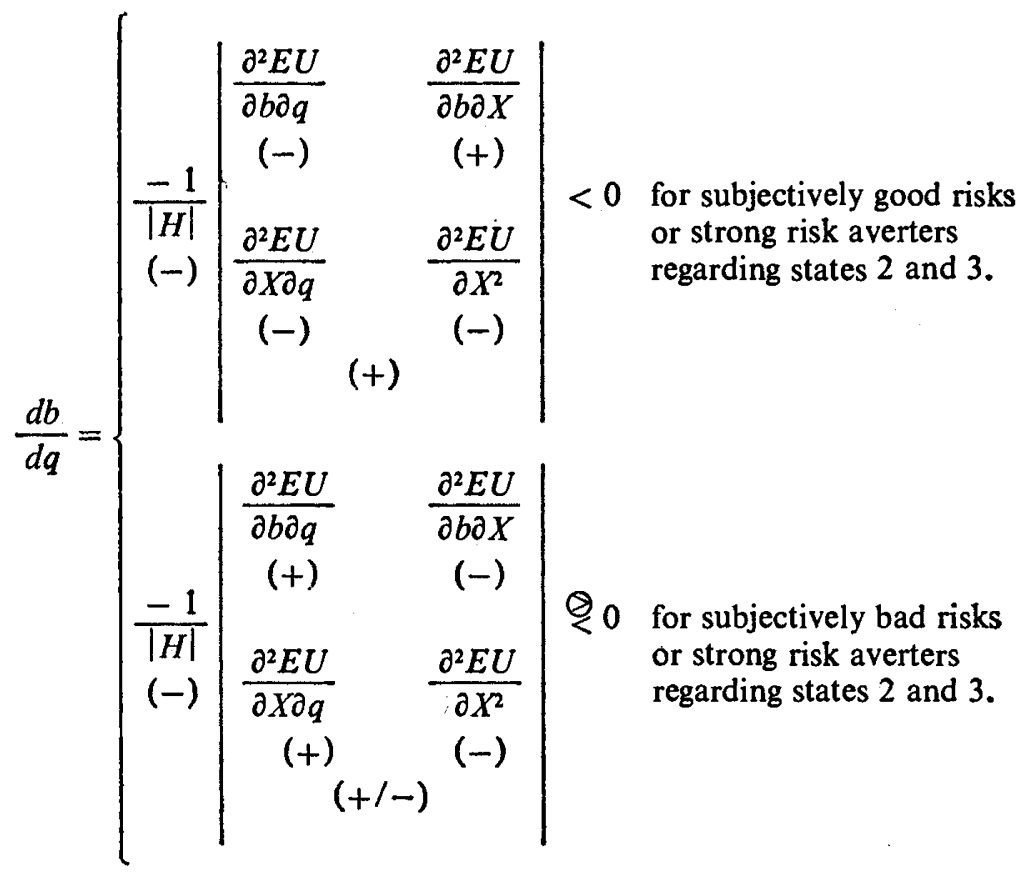

The implication $d b / d q>0$ for subjectively bad risks, while not being unambiguous, receives some support from the negative definiteness of the Hessian. This property constitutes a certain dominance of the diagonal elements (cf. Goldberger [1964], p. 36). Therefore, the absolute value of $\partial^{2} E U / \partial X^{2}$ will exceed the one of $\partial^{2} E U / \partial b \partial X$ as long as $\partial^{2} E U / \partial X^{2}$ and $\partial^{2} E U / \partial b^{2}$ are of comparable magnitude. The determinant in the lower part of eq. (26) would then tend to be negative. The prediction of the model can be formulated as follows: When prices for health care services rise, subjectively good risks will tend to decrease rather than increase coverage of the daily room rate. Subjectively bad risks who may well be a majority of the insured - may react either way because they assign some probability to the event of a hospitalization - planned or emergency. There is some presumption, to be tested empirically, that they will adjust their insurance coverage to the price increase, especially if they happen to put a high value on income stability in the case of hospitalization. ${ }^{11}$

11 Premiums for basic insurance are set to cover ambulatory care costs and all costs associated with treatment in the public ward of a hospital. These premiums were adjusted twice in the period 1976-1980 whereas premiums for supplementary hospital insurance remained unchanged. During this period, the equivalence principle assumed in eq. (8) was not fully adhered to, with the effect that the impact of a price change $(d q)$ on income $(Y)$ in state 1 is considerably mitigated. This serves to decrease the set of individuals whose predicted reaction is $(d b / d q<0, d X / d q<0)$, i.e. to keep good risks in the fund. Not surprisingly, private insurers have accused sick funds of subsidizing supplementary hospital insurance, which traditionally had been their domain. 
We now turn to the coverage of costs arising from stationary treatment. Using inequalities (22), (24) and (25), we obtain, in full analogy to (26)

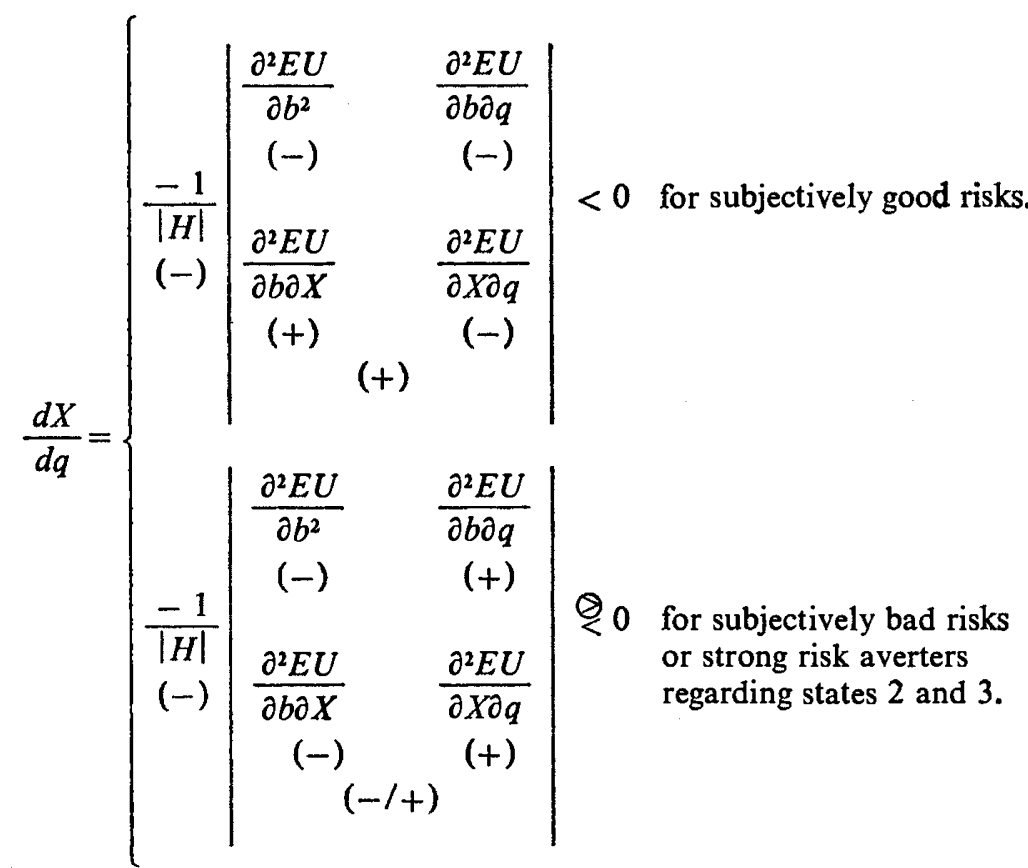

These implications correspond to those derived previously for $d b / d q$. Again, subjectively good risks will shy away from the increased cost of coverage. This reaction to rising prices in the health care sector cannot be entirely excluded for the subjectively mediocre and bad risks. But the more probable reaction certainly is an increase in the coverage of treatment outlays in the hospital.

\section{Special offers and the problem of adverse selection of risks}

We now wish to carry the analysis one step further. Swiss sick funds occasionally offer their members special conditions for the purchase of additional insurance. While being a competitive measure, these special offers also serve to speed up the insureds' adjustment to the price shock considered in the preceding section. Now the fact that a different direction of long-run adjustment may be expected for subjectively good and bad risks (cf. ineqs. (26) and (27) above) does not necessarily imply a different speed of reaction. However, a higher speed of reaction by bad risks could create an adverse selection problem in the transition period from one equilibrium situation to another. With adjustment lags estimated to be in the order of eight years or more, ${ }^{12}$

12 Estimates of the adjustment process proper imply lags of eight years and more, cf. Zweifel [1982 b]. 
attracting bad risks more quickly than good ones may suffice to throw a sick fund out of its financial equilibrium.

The sick fund Krankenkasse KKB (which provided most of the data to be analyzed in section 7 and 8 below) offered special conditions twice during the observation period. From September 1975 to September 1976, individuals having provisions of supplementary hospital insurance could increase their covered daily room rate $(b)$ by at most 50 francs and covered treatment costs by two increments, e.g. from 5,000 to 20,000 francs. Those previously not insured could opt for 50 francs and 3,000 francs, respectively. The crucial point of the offer was that usual reservation clauses with regard to age and current health status were waived. The same set of conditions was in effect starting July 1978 and ending March 1979, with the only modification that new treatment outlay insurance could be written up to an amount of 5,000 (instead of 3,000 ) francs. Although the sick fund did not alter actual premiums, the premium function as specified in eq. (8) was modified in the course of these two special offers. Giving members the opportunity to buy additional insurance irrespective of their current health status is equivalent to lowering the loading factor $(\theta)$ for individuals characterized by a high value of $(\bar{S})$ in terms of the model. They have a high risk of illness in the longer run, cf. eq. (1).

In the interest of simplicity, we will examine the impact of a general, undifferentiated change $d \theta$, neglecting certain non-price rationing elements such as the use of maximum allowable adjustments. Instead, we will focus on the question whether e.g. subjectively bad risks will additionally speed up an expected adjustment $d b / d q>0$ in response to a lowering of $(\theta)$. Since the empirical analysis will deal with the covered daily room rate $(b)$ only, we limit ourselves to the partial differentiation of ineq. (26). As will become clear from eqs. (30) to (32) below, the sign of $\partial \theta / \partial|H|$ is not determined. We therefore assume the determinant of the Hessian to be unaffected by the change $d \theta$, obtaining

$$
\frac{\partial}{\partial \theta}\left[\frac{d b}{d q}\right]=\frac{-1}{|H|} \cdot \frac{\partial}{\partial \theta}\left|\begin{array}{ll}
\frac{\partial^{2} E U}{\partial b \partial q} & \frac{\partial^{2} E U}{\partial b \partial X} \\
\frac{\partial^{2} E U}{\partial X \partial q} & \frac{\partial^{2} E U}{\partial X^{2}}
\end{array}\right|
$$

With regard to the first term, $\partial^{2} E U / \partial b \partial q$, we may refer to eq. (21). Treating $U_{Y Y}$, the indicator of absolute risk aversion with regard to income variation, as independent of $(\theta)$, we immediately obtain from eq. (21)

$$
\frac{\partial}{\partial \theta}\left[\frac{\partial^{2} E U}{\partial b \partial q}\right] \begin{cases}<0 & \text { for subjectively good risks, } \\
>0 & \begin{array}{l}
\text { for subjectively bad risks or strong risk averters } \\
\text { regarding state } 3 .
\end{array}\end{cases}
$$


Next, we note without proof

$$
\frac{\partial}{\partial \theta}\left[\frac{\partial^{2} E U}{\partial b \partial X}\right] \begin{cases}<0 & \text { for subjectively good risks, } \\ >0 & \text { for subjectively bad risks or strong risk averters } \\ \text { regarding state } 3 .\end{cases}
$$

For the term $\partial^{2} E U / \partial X \partial q$, the reference equation is eq. (23), differentiation of which yields three terms, all negative. Hence, we have

$$
\frac{\partial}{\partial \theta}\left[\frac{\partial^{2} E U}{\partial b \partial q}\right]<0 \text { for all insureds. }
$$

Up to this point, $\partial^{2} E U / \partial X^{2}$ has not been considered in detail because it is necessarily negative, cf. eq. (18). We now have to fill this gap. On the basis of eq. (14), using $\partial / \partial X\left[U_{Y}\right]=U_{Y Y} \partial Y / \partial X$ and the three state-dependent expressions for $\partial Y / \partial X$ assembled in eq. (15), we have

$$
\begin{aligned}
& \frac{\partial^{2} E U}{\partial X^{2}}=\int_{0}^{c}\left[U_{Y Y}\{(1+\theta) F\}^{2} 1 / f \cdot\right) d s \\
& +\int_{c}^{m}\left[-U_{Y Y}\{1-(1+\theta) F\}^{2}\right] f(\cdot) d s \\
& +\int_{c}^{m}\left[-U_{Y H}\{1-(1+\theta) F\} \frac{\partial L}{\partial K} \cdot \frac{\partial K}{\partial X}\right] f(\cdot) d s+\int_{c}^{m}\left[-U_{Y H} \cdot \frac{\partial L}{\partial K} \cdot \frac{\partial^{2} K}{\partial X^{2}}\right] f(\cdot) d s \\
& +\int_{m}^{1}\left[-U_{Y Y}\{1-(1+\theta) F\}^{2}\right] \mathcal{R}(\cdot) d s \\
& <0 \text {. }
\end{aligned}
$$

On the plausible assumption that $\partial^{2} K / \partial X^{2}$ is negative, partial differentiation of eq. (32) with respect to $(\theta)$ leads to the unambiguous result

$$
\frac{\partial}{\partial \theta}\left[\frac{\partial^{2} E U}{\partial X^{2}}\right]<0 \text { for all insureds. }
$$

Pulling the inequalities (29) $-(31)$ and (33) together and denoting them by $+\Delta$ and $-\Delta$, respectively, we finally obtain 


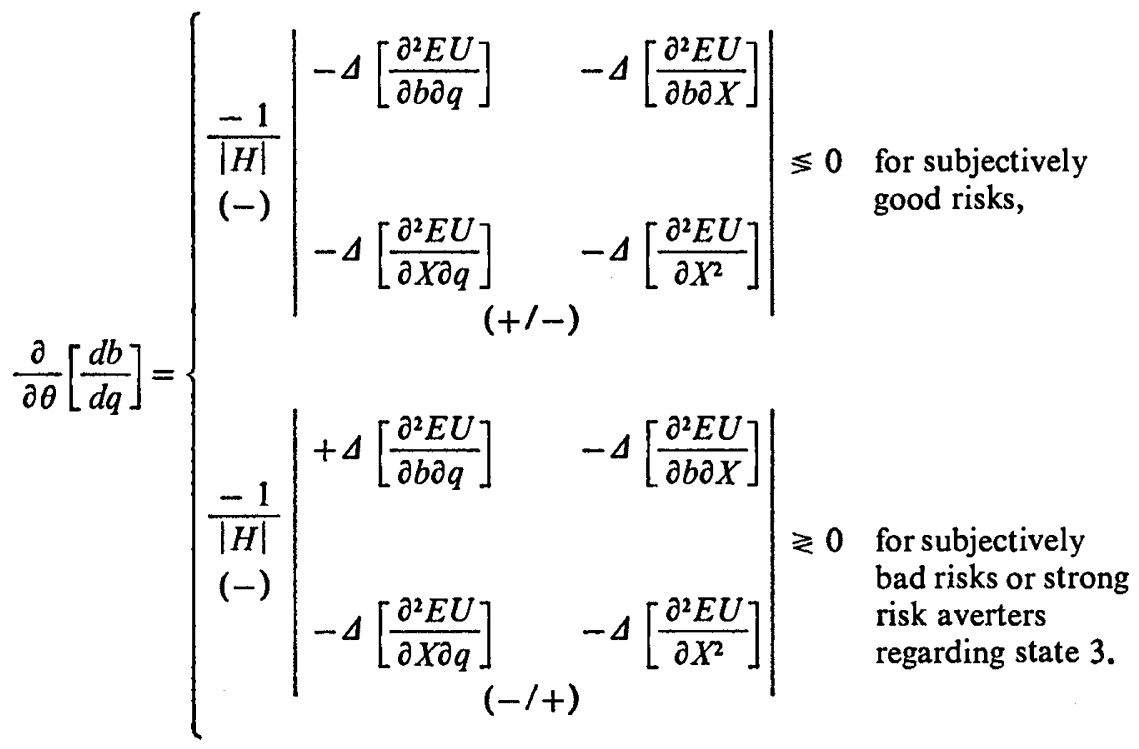

Contrary to what one might have expected, a lowering of the loading factor $(\theta)$ does not necessarily lead to a differential second-order reaction by subjectively good and bad risks. But if special offers should accomplish to keep the good risks in the system, implying $\partial / \partial \theta(d b / d q)<0$, then the diagonal elements in the upper part of ineq. (34) would have to outweigh the off-diagonal ones. Analogously, the diagonal terms in the lower part of ineq. (34) would again outweigh the off-diagonal ones, resulting in $\partial / \partial \theta(d b / d q)<0$ for subjectively bad risks, too. In other words, a reduction of the loading factor $(\theta)$ that is successful with the subjectively good risks will necessarily prompt subjectively bad risks and strong risk averters to speed up their adjustment towards higher coverage. Special offers by the sick fund are therefore predicted to inject a certain bias in favor of bad risks into the insurance. This is one of the key propositions to be tested in the empirical part of the paper.

\section{The data base}

The data base for this study comes from two merged sources. Source one is the history of the insurance status of a number of individuals over the years 1976-1980, kindly supplied by the sick fund Krankenkasse KKB. ${ }^{13}$ Source two is a mailed questionnaire survey. Following a pretest, 6400 members of the fund were asked to provide supplementary socioeconomic data in November 1980. Members of prime working

13 At this point, thanks are due to Dr. H. Schmid, director of the Krankenkasse KKB, for his continuing support of this project. Mr. P. Haas, head of the EDP division, did a splendid job in coordinating the mailing and coding of the questionnaires and making the insurance records available. 
age were oversampled to correct for their lower response rate. Of some 2300 responses, 2065 were sufficiently complete to be retained. Participation being voluntary, the respondent's time input had to be minimized. To accomplish this, all continuous variables (subjective health, income, length of work week, time spent on health promoting activities, marginal valuation of time, and travel and waiting time associated with a physician visit) were represented by a ray along which the respondent could just mark his position. This use of a modified visual analog scale allowed delicate variables to be measured with some precision while avoiding any resemblance with tax files. ${ }^{14}$ Much of the information gathered is not relevant for the demand for health insurance but will be relevant in a future analysis of health care utilization, given insurance. Table 1 contains the summary statistics of the variables actually used in this study and to be discussed below.

BDAILY. This is the dependent variable, corresponding to the theoretical decision variable $(b)$ of the preceding sections. It reflects the insurance status at the end of the year. In 1976, some $15 \%$ of the individuals in the sample had no insurance covering the daily charge for semiprivate or private accommodation with the sick fund Krankenkasse KKB. By 1980, the share of those opting for the public ward (or having purchased supplementary insurance from a private company) has dropped to $9 \%$. Hence, there seems to be no urgent need for turning to limited dependent variable estimation by Probit or Tobit methods. Theoretically, buyers and non-buyers of this type of insurance should differ little in economic terms because there is no financial barrier involved, minimal coverage costing about as much as a pack of cigarettes per month. By and large, the sampled members of KKB have adjusted their coverage in excess of hospital cost inflation. In 1980, BDAILY amounted to 72.5 Swiss francs per day (up by $32 \%$ from 1976), while the average daily room rate has increased by $17 \%$ for women and by $27 \%$ for men between 1976 and 1980, see Krankenkasse KKB [1981], p. 17. Due to the members having no coverage, the distribution of BDAILY was skewed to the left in 1976 but was almost symmetric in 1980 .

AGE. This reflects the age of the insured as of the beginning of 1981. With income held constant, we expect BDAILY to increase with age. Moreover, we

14 This is the scale used for labor income.

Q5. "Your employer spends a certain monthly amount on you (or you reckon your own wage if you are self-employed). This sum consists of wage costs and pro rata share of Christmas and other bonuses.

Please indicate the appropriate total cost (in thousands of Swiss francs):

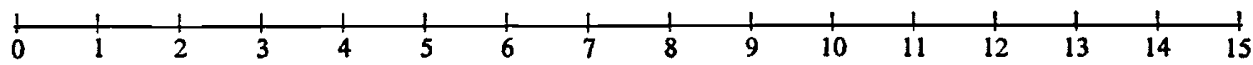

(Example: A designer costs his firm monthly a wage of sFr. 3000.-. Since the wage is paid thirteen times a year, the pro rata share is sFr. 250.-. The pro rata share of the extra Christmas bonus amounts

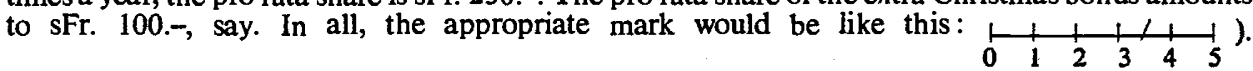

Visual analog scales have been in frequent use for testing a new drug with prospective consumers and are based on psychological research (McKelvie [1978]). But there, only endpoints are defined, e.g. "does not bother at all" and "unbearable" in the case of a drug's side effects. 
Table 1 : Descriptive statistics, all complete observations $(n=1692)$

\begin{tabular}{|c|c|c|c|c|c|}
\hline Symbol & Explanation & Year & Mean & SD. & Skewness \\
\hline AGE & Age as of January 1,1981 & 1980 & 44.2 & 16.2 & 0.647 \\
\hline BDAILY & $\begin{array}{l}\text { Covered daily room rate, } \\
\text { in SFr. }\end{array}$ & $\begin{array}{l}1976 \\
1980\end{array}$ & $\begin{array}{l}55.0 \\
72.5\end{array}$ & $\begin{array}{l}41.1 \\
42.7\end{array}$ & $\begin{array}{c}0.445 \\
-0.0398\end{array}$ \\
\hline CLAUSE & $\begin{array}{l}=1: \text { Reservation clause } \\
\text { in effect }\end{array}$ & $\begin{array}{l}1976 \\
1980\end{array}$ & $\begin{array}{l}0.0437 \\
0.0449\end{array}$ & $\begin{array}{l}0.205 \\
0.207\end{array}$ & $\begin{array}{l}4.47 \\
4.40\end{array}$ \\
\hline COMMERCE & $\begin{array}{l}=1: \text { Graduate of a school } \\
\text { of commerce }\end{array}$ & 1976 & 0.126 & 0.332 & 2.25 \\
\hline EMPLOYEE & $\begin{array}{l}=1: \text { Employee, public or } \\
\text { private }\end{array}$ & 1976 & 0.189 & 0.392 & 1.59 \\
\hline \multirow[t]{2}{*}{ INCOME } & \multirow{2}{*}{$\begin{array}{l}\text { Total income (labor, social } \\
\text { security, property), in } 10^{3} \\
\text { sFr. per month }\end{array}$} & 1976 & 2.48 & 1.39 & 1.23 \\
\hline & & 1980 & 3.07 & 1.56 & 1.05 \\
\hline PRIVATE & $\begin{array}{l}=1: \text { Member is in } \mathrm{P} 2 \text { or } \\
\mathrm{P} 3 \text { class (see text) }\end{array}$ & $\begin{array}{l}1976 \\
1980\end{array}$ & $\begin{array}{l}0.131 \\
0.129\end{array}$ & $\begin{array}{l}0.338 \\
0.335\end{array}$ & $\begin{array}{l}2.19 \\
2.18\end{array}$ \\
\hline \multirow[t]{2}{*}{ RATING } & \multirow{2}{*}{$\begin{array}{l}\text { Premium class according to } \\
\text { community rating, min. }=0 \text {, } \\
\max .=8\end{array}$} & 1976 & 3.43 & 2.19 & 0.349 \\
\hline & & 1980 & 3.81 & 1.93 & 0.478 \\
\hline SEXF & $=2:$ Individual is female & 1976 & 1.53 & 0.499 & -0.111 \\
\hline SUBSID & $\begin{array}{l}=1: \text { Individual qualifies } \\
\text { for a premium subsidy }\end{array}$ & $\begin{array}{l}1976 \\
1980\end{array}$ & $\begin{array}{l}0.0526 \\
0.0414\end{array}$ & $\begin{array}{l}0.223 \\
0.199\end{array}$ & $\begin{array}{l}4.01 \\
4.61\end{array}$ \\
\hline
\end{tabular}

hypothesize the age gradient to be particularly steep in the wake of a special offer by the sick fund, due to the waiving of reservation clauses with regard to age and current health status ; cf. the discussion in section 6.

CLAUSE. About $4 \%$ of the insureds contained in this sample had to accept reservation clauses when applying for higher coverage. Such clauses specify the health conditions for which only the previously contracted daily room rate will be covered. They are not waived at the time of a special offer but expire after a period of five years. As these individuals are considered to be bad risks by the fund, we would expect them to judge themselves to be bad risks as well. Therefore, they should be characterized by a higher value of BDAILY than others. Although they probably wish to adjust their coverage to cost inflation (see ineq. (26) of section 5) they are prevented from doing so. Moreover, they cannot take advantage of special offers. Hence, we hypothesize a positive partial relationship between BDAILY and CLAUSE, with little change over the five years considered. 
COMMERCE. This is a dummy variable which takes on the value of one if the insured has graduated from a commercial school. Without necessarily being more risk averse than others, these individuals should have increased awareness of risks and insurance as one means for coping with them. On the other hand, their superior knowledge might result in a more precise estimate of the actual probability of hospitalization, possibly overestimated by others. Hence, no a priori statement about the partial effect of COMMERCE on BDAILY seems possible.

EMPLOYEE. This category includes many officials of the public sector. ${ }^{15}$ Other things equal, the choice of a public employer can be taken as a sign of risk-aversion. According to ineqs. (26) and (34) of section 5 and 6, we expect this group to opt for high coverage and to take advantage of special offers.

INCOME. In the questionnaire, one item is labor income, another, income from other sources. Since phenomena related to time costs should not be relevant for the choice of BDAILY, the two items can be aggregated. In this way, retired members of the fund, for whom social security payments are the most important and often only source of income, need not be excluded from the sample. According to the theoretical model, which focuses on the dynamics of adjustment and therefore abstracts from the amenities associated with a higher room rate, income $(Y)$ influences demand for hospital insurance only through its effects on the marginal utility income $\left(U_{Y}\right)$, cf. eq. (13). Little is known about that relationship. On the other hand, demand for hotel amenities of a hospital should be reflected by BDAILY at a given point in time. For although Swiss sick funds belong to the domain of social insurance, complementary hospital insurance buys claims to a perfectly private good, viz. better accommodation. Thus, a positive partial impact on BDAILY is to be expected, with special offers leaving its value unaffected.

PRIVATE. The sick fund Krankenkasse KKB distinguishes three membership classes, with the coinsurance rate for ambulatory care approaching $10 \%$ throughout.16 The general P1 class comprises individuals with medium to low family incomes. P1 members pay a deductible of sFr. 30 per episode of ambulatory care as well as rather low premiums. The well-to-do are requested to be in the $\mathrm{P} 2$ class, where premiums are about $30 \%$ higher and the deductible is sFr. 50. On the other hand, physicians are allowed to bill a $45 \%$ surcharge for the treatment of a P2 patient. Moreover, P2 members have the option of registering as private patients (P3). Here, the deductible amounts to $80 \mathrm{sFr}$., with physicians being free to charge what the market will bear. Thus, P2 and particularly P3 member enjoy priority access to ambulatory care; presumably this is an important advantage for a high wage earner or an individual who considers himself not too good a health risk. Since there are very few P3 members in the sample, PRIVATE takes on the value of one if the individual belongs to either the P2 or the P3 class. Due to the income effect, we expect PRIVATE members to be more fully covered ; due to the possible risk effect, they might take particular advantage of special offers as well.

15 The sick fund Krankenkasse KKB has its stronghold in the canton of Bern. The city of Bern is the Swiss capital. Hence, the EMPLOYEE category will be made up largely of public employees and government officials.

16 See fn. 3. 
RATING. Swiss sick funds generally structure their premiums according to a community rating scale, thus taking regional morbidity and cost differences into account. If an individual has a high value of RATING, he probably lives in a region where hospitals are expensive. Such individuals have an incentive to opt for particularly high coverage and to take advantage of special offers. For simplification, RATING is used as a cardinal variable, with values between 0 and 8 , although it is measured on an ordinal scale only.

SEXF. According to the statistics compiled by the sick fund (see Krankenkasse KKB [1981], p. 16), female members $(S E X F=2)$ run a risk of hospitalization roughly double that of male ones, while a day in hospital day costs them only slightly less. Therefore, women should consider themselves more at risk than men $(\mathrm{SEXF}=1)$. Based on inequalities (26) and (34), we predict a positive partial relationship between SEXF and BDAILY ceteris paribus, with special offers adding to its size.

SUBSID. This variable takes on the value of one if the individual's basic premium, covering ambulatory care and stationary care in a public ward, is subsidized. This subsidy is not tied to any restrictions regarding the purchase of supplementary hospital insurance. As a matter of fact, in 1976 BDAILY was as high as $100 \mathrm{sFr}$. for subsidized individuals of the sample. But since persons qualifying for the subsidy must live in a low-income household, we predict the partial relationship of SUBSID with BDAILY to be negative. Inasmuch the majority of this group does put up with basic insurance and is therefore fully covered for all expenses in the public ward, a price change $(d q)$ should have no first-order effect on the sign of ineq. (26). Few individuals in this group would have an incentive to respond to the special offers of the sick fund. Since the regression coefficient of SUBSID will mirror a second-order effect relative to the rest of the sample, it may increase in absolute value following a special offer.

\section{Econometric results}

The empirical analysis of a file containing several hundred variables inevitably leads to a certain amount of specification search. However, such regression strategies have serious consequences for the interpretation of statistical tests (Bock et al [1973], Leamer [1978], Ch. 5). For this reason, about half of the sample was reserved for final testing from the very beginning. For matching purposes, the sick fund Krankenkasse KKB identified each individual with a key. Retaining even-keyed respondents resulted in a subsample of 876 complete observations. The estimation results of this subsample are presented in Table 2.

The majority of the hypotheses formulated in the preceding section are confirmed. In particular, the age gradient (AGE) of BDAILY is about 0.3 in 1976 and 1977 but increases to 0.46 in 1979. In view of the small estimated standard errors, this structural change is likely to be statistically significant. There is a clear sex differential (SEXF) which also increases markedly in the wake of the 1978/79 special offer. Supplementary hospital insurance apparently is a normal economic good; the estimated income elasticity of BDAILY, evaluated at the means, rises slightly from $0.18(=3.99 \cdot 2.48 / 55)$ in 1976 to $0.19(=4.43 \cdot 3.07 / 72.5)$ in 1980 , see Tables 1 and 2 . Female members do in fact seem to judge themselves to be comparatively mediocre risks; in 1976 already, 
Table 2 : OLS regressions for BDAILY (covered daily room charge), even-keyed subsample $\left(n_{1}=876\right)$

\begin{tabular}{|c|c|c|c|c|c|}
\hline $\begin{array}{c}\text { Explanatory } \\
\text { variable }\end{array}$ & $1976^{\circ}$ & 1977 & 1978 & $1979^{\circ}$ & 1980 \\
\hline CONSTANT & $\begin{array}{r}-1.31 \\
(5.49)\end{array}$ & $\begin{array}{r}-2.58 \\
(5.85)\end{array}$ & $\begin{array}{r}-1.97 \\
(6.21)\end{array}$ & $\begin{array}{c}-0.844 \\
(6.69)\end{array}$ & $\begin{array}{c}6.06 \\
(6.83)\end{array}$ \\
\hline AGE & $\begin{array}{c}0.298^{* *} \\
(0.0786)\end{array}$ & $\begin{array}{c}0.301^{* *} \\
(0.0805)\end{array}$ & $\begin{array}{c}0.330 * * \\
(0.0831)\end{array}$ & $\begin{array}{c}0.458^{* *} \\
(0.0871)\end{array}$ & $\begin{array}{c}0.449 * * \\
(0.0868)\end{array}$ \\
\hline CLAUSE & $\begin{array}{l}17.8^{*} \\
(5.80)\end{array}$ & $\begin{array}{l}16.9^{*} \\
(5.78)\end{array}$ & $\begin{array}{l}16.2^{*} \\
(6.027)\end{array}$ & $\begin{array}{l}14.9 \\
(6.33)\end{array}$ & $\begin{array}{l}14.8 \\
(5.96)\end{array}$ \\
\hline SEXF & $\begin{array}{l}7.94 * \\
(2.45)\end{array}$ & $\begin{array}{l}8.62^{*} \\
(2.50)\end{array}$ & $\begin{array}{l}10.6^{* *} \\
(2.58)\end{array}$ & $\begin{array}{l}14.1^{* *} \\
(2.69)\end{array}$ & $\begin{array}{l}13.7 * * \\
(2.66)\end{array}$ \\
\hline PRIVATE & $\begin{array}{l}23.0 * * \\
(3.82)\end{array}$ & $\begin{array}{l}21.6 * * \\
(3.99)\end{array}$ & $\begin{array}{c}24.9 * * \\
(4.05)\end{array}$ & $\begin{array}{l}23.1 * * \\
(4.24)\end{array}$ & $\begin{array}{l}20.8 * * \\
(4.21)\end{array}$ \\
\hline SUBSID & $\begin{array}{r}-11.3 \\
(5.40)\end{array}$ & $\begin{array}{l}-10.7 \\
(6.46)\end{array}$ & $\begin{array}{c}-15.1 \\
(6.44)\end{array}$ & $\begin{array}{r}-21.7^{*} \\
(6.89)\end{array}$ & $\begin{array}{c}-23.3 * * \\
(6.56)\end{array}$ \\
\hline INCOME & $\begin{array}{c}3.99 * * \\
(0.937)\end{array}$ & $\begin{array}{c}5.00^{* *} \\
(0.943)\end{array}$ & $\begin{array}{c}4.09^{* *} \\
(0.957)\end{array}$ & $\begin{array}{c}4.70 * * \\
(0.989)\end{array}$ & $\begin{array}{c}4.43^{* *} \\
(0.928)\end{array}$ \\
\hline COMMERCE & $\begin{array}{l}13.9^{* *} \\
(3.71)\end{array}$ & $\begin{array}{l}15.0^{* *} \\
(3.95)\end{array}$ & $\begin{array}{l}14.7^{* *} \\
(3.91)\end{array}$ & $\begin{array}{l}16.0 * * \\
(3.93)\end{array}$ & $\begin{array}{l}15.2 * * \\
(4.02)\end{array}$ \\
\hline EMPLOYEE & $\begin{array}{l}10.0 * * \\
(3.13)\end{array}$ & $\begin{array}{l}11.3^{* *} \\
(3.20)\end{array}$ & $\begin{array}{l}11.0 * * \\
(3.30)\end{array}$ & $\begin{array}{l}14.4^{* *} \\
(3.43)\end{array}$ & $\begin{array}{l}13.9^{* *} \\
(3.38)\end{array}$ \\
\hline RATING & $\begin{array}{c}4.71 * * \\
(0.573)\end{array}$ & $\begin{array}{c}4.13 * * \\
(0.604)\end{array}$ & $\begin{array}{c}4.35 * * \\
(0.641)\end{array}$ & $\begin{array}{c}2.81 * * \\
(0.686)\end{array}$ & $\begin{array}{c}2.08^{* *} \\
(0.928)\end{array}$ \\
\hline $\mathbf{R}^{2}$ & 0.27 & 0.25 & 0.25 & 0.24 & 0.22 \\
\hline S.E. regression & 35.0 & 35.8 & 36.9 & 38.4 & 37.8 \\
\hline $\mathbf{F}$ & 36.0 & 31.9 & 31.4 & 29.8 & 26.2 \\
\hline
\end{tabular}

- Years with special offer by the fund (see text).

* Coefficient significant at the 0.01 confidence level or better (two-tailed test).

** Coefficient significant at the 0.001 confidence level or better (two-tailed test).

Note : Estimated standard errors in parentheses.

they had opted for almost 8 francs higher coverage, $15 \%$ more than the average of the sample. But the decisive test is to see whether or not this differential is related to the special offers made by the sick fund. There is indeed evidence to such an effect, as the differential increases from an estimated 8 francs in 1976 and 1977 to almost 
14 francs in 1979 and 1980. In contradistinction, the regression coefficient of COMMERCE, while being positive, remains roughly constant between 1976 and 1980 . The one prediction not borne out concerns the impact of RATING. Individuals living in a community that is rated high face a higher financial risk in the case of hospitalization

Table 3 : OLS regressions for BDAILY (covered daily room charge), entire sample $(n=1692)$

\begin{tabular}{|c|c|c|c|c|c|}
\hline $\begin{array}{c}\text { Explanatory } \\
\text { variable }\end{array}$ & $1976^{\circ}$ & 1977 & 1978 & $1979^{\circ}$ & 1980 \\
\hline CONSTANT & $\begin{array}{r}-1.50 \\
(4.04)\end{array}$ & $\begin{array}{r}-2.61 \\
(4.25)\end{array}$ & $\begin{array}{r}-2.01 \\
(4.50)\end{array}$ & $\begin{array}{c}-0.948 \\
(4.85)\end{array}$ & $\begin{array}{c}4.84 \\
(4.99)\end{array}$ \\
\hline AGE & $\begin{array}{c}0.189^{* *} \\
(0.0540)\end{array}$ & $\begin{array}{c}0.182^{* *} \\
(0.0553)\end{array}$ & $\begin{array}{c}0.202^{* *} \\
(0.0575)\end{array}$ & $\begin{array}{l}0.307^{* *} \\
(0.0605)\end{array}$ & $\begin{array}{c}0.304^{* *} \\
(0.0608)\end{array}$ \\
\hline CLAUSE & $\begin{array}{l}21.5 * * \\
(4.18)\end{array}$ & $\begin{array}{l}21.1 * * \\
(4.15)\end{array}$ & $\begin{array}{l}22.6^{* *} \\
(4.36)\end{array}$ & $\begin{array}{l}22.1 * * \\
(4.69)\end{array}$ & $\begin{array}{l}21.8^{* *} \\
(4.48)\end{array}$ \\
\hline SEXF & $\begin{array}{l}8.60 * * \\
(1.73)\end{array}$ & $\begin{array}{l}8.91 * * \\
(1.76)\end{array}$ & $\begin{array}{l}10.3 * * \\
(1.82)\end{array}$ & $\begin{array}{l}14.7 * * \\
(1.90)\end{array}$ & $\begin{array}{l}14.8^{* *} \\
(1.89)\end{array}$ \\
\hline PRIVATE & $\begin{array}{l}22.8^{* *} \\
(2.76)\end{array}$ & $\begin{array}{l}21.6^{* *} \\
(2.86)\end{array}$ & $\begin{array}{l}22.8 * * \\
(2.95)\end{array}$ & $\begin{array}{c}24.2 * * \\
(3.08)\end{array}$ & $\begin{array}{l}22.7^{* *} \\
(3.07)\end{array}$ \\
\hline SUBSID & $\begin{array}{r}-12.0 * \\
(3.90)\end{array}$ & $\begin{array}{r}-12.0 * \\
(4.62)\end{array}$ & $\begin{array}{c}-14.3^{*} \\
(4.70)\end{array}$ & $\begin{array}{c}-19.1 * * \\
(4.99)\end{array}$ & $\begin{array}{c}-21.5 * * \\
(4.83)\end{array}$ \\
\hline INCOME & $\begin{array}{c}4.24^{* *} \\
(0.672)\end{array}$ & $\begin{array}{c}5.24^{* *} \\
(0.678)\end{array}$ & $\begin{array}{c}4.82 * * \\
(0.688)\end{array}$ & $\begin{array}{c}5.26^{* *} \\
(0.709)\end{array}$ & $\begin{array}{c}5.06 * * \\
(0.682)\end{array}$ \\
\hline COMMERCE & $\begin{array}{l}14.7^{* *} \\
(2.61)\end{array}$ & $\begin{array}{l}15.2 * * \\
(2.65)\end{array}$ & $\begin{array}{l}14.8 * * \\
(2.74)\end{array}$ & $\begin{array}{l}14.6 * * \\
(2.86)\end{array}$ & $\begin{array}{l}13.3 * * \\
(2.84)\end{array}$ \\
\hline EMPLOYEE & $\begin{array}{l}8.66^{* *} \\
(2.23)\end{array}$ & $\begin{array}{l}9.13 * * \\
(2.27)\end{array}$ & $\begin{array}{l}9.45 * * \\
(2.35)\end{array}$ & $\begin{array}{l}10.9 * * \\
(2.45)\end{array}$ & $\begin{array}{l}10.9 * * \\
(2.43)\end{array}$ \\
\hline RATING & $\begin{array}{l}5.17^{* *} \\
(0.399)\end{array}$ & $\begin{array}{c}4.87^{* *} \\
(0.424)\end{array}$ & $\begin{array}{c}4.94^{* *} \\
(0.448)\end{array}$ & $\begin{array}{c}3.35 * * \\
(0.483)\end{array}$ & $\begin{array}{c}2.44^{* *} \\
(0.493)\end{array}$ \\
\hline $\mathbf{R}^{2}$ & 0.29 & 0.27 & 0.26 & 0.24 & 0.22 \\
\hline S.E. regression & 34.8 & 35.3 & 36.5 & 38.1 & 37.8 \\
\hline $\mathbf{F}$ & 75.8 & 69.6 & 66.4 & 60.2 & 53.2 \\
\hline
\end{tabular}

- Years with special offer by the fund (see text).

* Coefficient significant at the 0.01 confidence level or better (two-tailed test).

** Coefficient significant at the 0.001 confidence level or better (two-tailed test).

Note: Estimated standard errors in parentheses. 
and are therefore expected to adjust their coverage to a greater degree than others when offered special conditions. However, this does not seem to be the case, as the estimated regression parameter decreases from about 5 francs to 2 francs.

These findings are still very tentative, however. For the estimates could be the accidental result of specification search. In an attempt to test for such an effect, we rerun the same regressions, but based on the odd-keyed subsample and the entire sample. Sparing the reader the details of the odd-keyed subsample, we turn to the estimates based on the entire sample, contained in Table 3.

With regard to the age gradient of BDAILY, we note at once that for 1976 and 1977, the coefficients of AGE are of the order of 0.2 instead of 0.3 . On the other hand, there are again signs of a structural break between 1978 and 1979 as the coefficient jumps to over $0.3,1979$ being the year of the second special offer. The hypothesis that such special offers tend to create problems of adverse selection receives additional support by the fact that female members are again estimated to have opted for 15 francs more coverage in 1979 and 1980, compared to 9 francs in 1976 and 1977. By way of contrast, the stable coefficient of CLAUSE mirrors the effectiveness of the reservation clauses applied to "objectively" bad risks.

Supplementary hospital insurance is confirmed to be a normal economic good, in 1980 even somewhat more so than in 1976. But the increase of the coefficient of INCOME does not seem to be linked with the special offers made by the sick fund. The stability of the parameter estimate of PRIVATE also speaks in favor of an unchanged income effect : In 1976 as well as in 1980, members of the P2 and the P3 classes have opted for a value of BDAILY that is about 23 francs higher, ceteris paribus.

For a final comparison of the estimates based on the two subsamples and the full sample, we construct a series of statistical tests. Since the estimated standard errors do not differ much between subsamples (see bottom of Tables 2 and 3), we may proceed on the assumption that the true error variance has the same value in the two sets. Following Theil ([1971], p. 147), an F test is used to determine whether or not the hypothesis can be maintained that regression parameters for even- and odd-keyed individuals are in fact equal. If the true parameters differ, forcing the estimated coefficients to be the same (as in Table 3) should result in a significant deterioration of fit compared to letting them vary accross the two subsamples. The relevant statistics have been compiled in Table 4.

After correction for changing degrees of freedom, the deterioration of fit remains well below the critical value up to 1978 . It is barely below the critical value for 1979 and exceeds it for 1980 . This pattern suggests that the hypothesis of equality should be rejected for 1980 and possibly 1979. A possible reason for the apparent drifting apart of the two subsamples is discussed below.

In all, the predictions formulated on the basis of the theoretical model are borne out to a considerable degree. However, the following three points, bearing on the interpretation of the econometric evidence presented, merit special attention.

The first has to do with the increasingly negative value of the coefficient of SUBSID. By 1980 , subsidized low-income members on average had $22 \mathrm{sFr}$. less coverage 
Table 4: Testing the compatibility of the subsample regressions

\begin{tabular}{|l|c|c|c|c|c|}
\hline \multicolumn{1}{|c|}{ Statistic } & $1976^{\circ}$ & \multicolumn{1}{c|}{1977} & \multicolumn{1}{c|}{1978} & \multicolumn{1}{c|}{$1979^{\circ}$} & \multicolumn{1}{c|}{1980} \\
\hline$S S E_{1}$ (even-keyed) & $1,051,473$ & $1,096,764$ & $1,167,552$ & $1,260,429$ & $1,225,828$ \\
$S S E_{2}$ (odd-keyed) & 963,282 & 986,136 & $1,057,811$ & $1,159,758$ & $1,151,398$ \\
$S S E_{T}$ (entire sample) & $2,027,728$ & $2,099,547$ & $2,245,802$ & $2,445,847$ & $2,404,000$ \\
$S S E_{T} /\left(S S E_{1}+S S E_{2}\right)-1$ & 0.00644 & 0.00799 & 0.00918 & 0.0106 & 0.0113 \\
(relative deterioration & & & & & \\
of fit) & & & & & \\
\hline$F(10,1672)^{*}$ & 1.08 & 1.34 & 1.53 & 1.77 & 1.88 \\
$F^{c}(\infty, 0.05)$ & 1.83 & 1.83 & 1.83 & 1.83 & 1.83 \\
\hline
\end{tabular}

- Years with special offer (see text).

* The d.f. correction is given by $\left(n_{1}+n_{2}-2 K\right) / K=(866+826-20) / 10=167.2$, where $K$ symbolizes the number of regressors.

in terms of BDAILY than others, ceteris paribus, up from $12 \mathrm{sFr}$. five years earlier (see Table 3). As there is a rather clear jump from $1976 / 77$ to $1979 / 80$, it is tempting to infer that the special offer of $1978 / 79$ has resulted in an increased disparity of insurance coverage between income classes. Special offers by the sick fund could be therefore blamed of favoring high-income individuals, in contradiction to the stability of the income elasticity of BDAILY noted above. Such an inference is not well founded, however. The majority of the subsidized members do not buy supplementary hospital insurance at all but rather opt for the full coverage of outlays in the public ward provided by basic insurance. Hence, there is no necessity for them to adjust their policy to increased daily room rates. But then, the increased differential between subsidized and other individuals can be given another interpretation. It mirrors the general adjustment of the nonsubsidized members that was induced by the special offer regardless of personal risk considerations like age, sex, and community rating. This "pure" increase by $10 \mathrm{sFr}$. (relative to the nonaffected subsidized group) therefore provides an estimate of the adjustment deemed necessary in view of the general cost inflation in the health care sector. This "pure" adjustment amounts to $18 \%$ of $55 \mathrm{sFr}$., the average value of BDAILY in 1976. It corresponds roughly to the increase of the average room rate of $17 \%$ for women and $27 \%$ of men, cf. the discussion of Table 1 . The tendency towards overshooting noted there turns out to be less salient when certain personal characteristics associated with increasing risk are taken into due account.

The second point refers to the rôle of the community rating variable as a predictor of BDAILY. The significantly positive coefficient of RATING constitutes evidence in favor of the view that regional cost differences lead to differences in coverage, as predicted by the theoretical model when the change $(d q)$ is interpreted as a regional difference in ineq. (26). But why should this effect decrease rather than increase in a time of cost inflation? One possible answer is that we are dealing with a statistical 
artifact. Community ratings are subject to yearly revision, and the majority of communities have moved upwards on the scale. Hence, an additional point on the rating scale may mirror quite another difference in terms of service price $(q)$ in 1980 than in 1976. Another, equally plausible explanation is this. Daily costs in the hospital $(q)$ have in fact tended to equalize across communities in the course of the 1970's. The small rural hospitals began to open up new departments and to equip them with the latest technology. Due to their improved quality of service, they could catch up with urban hospitals in their pricing. The gradual decrease of the regression coefficient of RATING can therefore be interpreted as a consequence of vanishing regional differences in the daily room rate.

The third and final point relates to the observation that the two subsamples seem to be drifting apart, made in the context of Table 4 . At the root of the phenomenon may well be the general loss of explanatory power of the estimated equation, however. For $1976,29 \%$ of the variance of BDAILY could be explained, for $1980,22 \%$ only (cf. bottom of Table 3 and similarly in Table 2). Apparently, factors influencing the demand for insurance coverage but not yet accounted for make themselves increasingly felt. In view of the continuing cost inflation and the predicted differences in reaction to it, an increasing share of unexplained variability is to be expected. For we have been taking the first-order effects implied by ineqs. (26) as given, focusing on the second-order effects induced by special offers instead. However, estimates of the expected financial risk associated with a hospital stay (but exclusive of treatment costs) by sex and age class have failed to contribute significantly to the modeling of both first- and second order effects. Quite possibly it is the individual's personal cost sharing experience rather than average values of financial risk that shape his demand for future insurance coverage. Work currently under way is directed at exploring this possibility. ${ }^{\mathbf{1 7}}$

\section{Conclusions}

Demand for health insurance is an important element in the alleged costinsurance spiral operating in the Swiss health care sector. Only if a majority of the insured react to an increase in the price of medical services by increasing their relative coverage in spite of higher premiums does the spiral continue to turn. In an attempt to take the institutional conditions prevailing in Switzerland (and to some extent in other European countries) into due account, an economic model of the demand for supplementary hospital insurance was formulated. It contains two decision variables: $(b)$, the daily rate for a semiprivate or private room covered by the policy, and $(X)$, the costs of stationary treatment as a private or semiprivate patient. The model can be used to predict the likely adjustment of the insured to an increase of

17 Individual utilization and cost sharing information for the 2065 individuals of the sample is available and can be used for modeling the adjustment of insurance coverage to increases in the cost of health care; see Zweifel [1982 b]. 
prices in health care, depending upon whether they subjectively conceive of themselves as good or bad risks and on their degree of financial risk aversion. From time to time, Swiss sick funds seek to speed up the adjustment process by making special offers in the course of which reservation clauses bearing on age and current health are waived. Therefore, an analysis of second-order effects was carried out. The model predicts that a special offer which accomplishes to keep subjectively good risks in the fund necessarily induces subjectively bad risks to accelerate their transition to higher coverage. This prediction was empirically tested with regard to the covered daily room rate using some 1600 individual insurance records over the years 1976-1980. These records were supplied by a major Swiss sick fund and complemented by socioeconomic data coming from a mailed questionnaire survey. It was found that highrisk individuals (members of higher age, of female sex, and living in highly rated communities) indeed took particular advantage of a special offer made in 1978/79. However, the explanatory power of the estimated relationship decreases during the observation period, probably because the impact of cost inflation on the demand for insurance as such was not explicitly accounted for in the empirical part of this study. This task will be addressed in future work.

\section{REFERENCES}

ARROW, K. J. [1965] : "Aspects of the theory of risk-bearing", Yrijö Jahnsson Lectures, Helsinki, Yrijö Jahnsson Säätiö.

ARROW, K. J. [1970] : Essays in the Theory of Risk-Bearing, North-Holland, Amsterdam.

BECKER, G. S. [1965] : "A theory of the allocation of time", Economic Journal (September 1965), 493-517.

BOCK, M. G., YANCEY, T. A., and JUDGE, G. W. [1973] : “The statistical consequences of preliminary test estimators in regression", Journal of the American Statistical Association, 68, 109-116.

BORCH, K. [1974] : The Mathematical Theory of Insurance. An Annotated Selection of Papers on Insurance Published 1960-1972, Heath \& Co., Lexington, Mass.

CAIRNS, J. A., and SNELL, M. C. [1978] : "Prices and the demand for care", in Culyer, A.J., and Wright, K. G. (Eds.) : Economic Aspects of Health Services, Martin Robertson, London, 95-122.

CHIANG, A. C. [1974] : Fundamental Methods of Mathematical Economics, McGraw-Hill International Student Edition, Tokyo.

EHRLICH, I., and BECKER, G.S. [1972] : "Market insurance, self-insurance, and selfprotection", Journal of Political Economy, 80 (July-August 1972), 623-648.

EISEN, R. [1979] : Theorie des Versicherungsgleichgewichts, Duncker \& Humblot, Berlin.

FELDSTEIN, M.S. [1973]: “The welfare loss of excess health insurance", Journal of Political Economy, 81 (April 1973), 251-280.

FRIEDMAN, B. [1974] : "Risk aversion and the consumer choice of health insurance option", Review of Economics and Statistics, 56, 209-214. 
GOLDBERGER, A.S. [1964] : Econometric Theory, J. Wiley \& Sons, New York.

HENDERSON, J. M., and QUANDT, R.E. [1971] : Microeconomic Theory. A Mathematical Approach, McGraw-Hill International Student Edition, Tokyo.

KRANKENKASSE KKB [1981] : 111. Jahresbericht, 1. Januar bis 31. Dezember 1980 (Annual Report No. 111), Bern.

LEAMER, E. E. [1978] : Specification Searches. Ad hoc Inference with Nonexperimental Data, J. Wiley \& Sons, New York.

MANNING, W. G., NEWHOUSE, J. P., and WARE, J. E. Jr. [1980] : "The status of health in demand estimation: Beyond excellent, good, fair, and poor". Paper prepared for the NBER Conference on Economic Aspects of Health, Palo Alto, July 30-31, 1980.

MANNING, W.G. [1981] et al.: "A two-part model of the demand for medical care: Preliminary results from the health insurance study", in : Perlman, $M$. and van der Gaag, J. (Eds.), Health, Economics, and Health Economics, North Holland, Amsterdam.

MCKELVIE, S. K. [1978] : "Graphical rating scales: How many categories?", British Journal of Psychology, 69, 185-202.

MOSSIN, J. [1968] : "Aspects of rational insurance purchasing", Journal of Political Economy, 76 (August 1968), 553-568.

NEWHOUSE, J.P., and PHELPS, Ch.E. [1976] : "New estimates of price and income elasticities of medical services", in: Rosett, R. N. (Ed.), The Role of Health Insurance in the Health Services Sector, Universities-NBER Conference Series No. 27, Neale Watson, New York, 261-312.

PHELPS, Ch.E. [1973]: Demand for Health Insurance: A Theoretical and Empirical Investigation, R-1054, OEO, Rand Corporation, Santa Monica.

PHELPS, Ch. E. [1976] : "Demand for reimbursement insurance", in : Rosett, R.N. (Ed), The Role of Health Insurance in the Health Services Sector, Universities-NBER Conference Series No. 27, Neale Watson, New York, 115-155.

PRATT, J.W. [1964] : "Risk aversion in the small and in the large", Econometrica, 32 (January-April 1964), 122-136.

ROTHSCHILD, M., and STIGLITZ, J. [1976] : "Equilibrium in competitive insurance markets : An essay on the economics of imperfect information", Quarterly Journal of Economics, 90 (November 1976), 629-649.

SCHMID, H. [1978]: “Kostenbeteiligung in der Krankenversicherung", Schweizerische Aerztezeitung, 45, 1995-2003.

SLOAN, F. A. [1976] : "Physician fee inflation : Evidence from the late 1960s", in : Rosett, R. N. (Ed), The Role of Health Insurance in the Health Services Sector, National Bureau of Economic Research and Neale Watson, New York, 321-354.

SLOAN, F. A., and LORANT, J. [1977] : "The role of waiting time: Evidence from physicians' practices", Journal of Business, 50 (October 1977), 486-509.

STARR, R. M. [1973] : “Optimal production and allocation under uncertainty", Quarterly Journal of Economics, 87 (February 1973), 81-95.

STEINWALD, B., and SLOAN, F. A. [1974] : "Determinants of physicians' fees", Journal of Business, 47 (October 1974), 493-507.

THEIL, H. [1971] : Principles of Econometrics, J. Wiley \& Sons, New York. 
ZECKHAUSER, R. [1970] : "Medical insurance : A case study of the tradeoff between risk spreading and appropriate incentives ", Journal of Economic Theory, 2, 10-26.

ZWEIFEL, P. [1981] : "Supplier-induced demand in a model of physician behavior", in : Perlman, M. and van der Gaag, J. (Eds.) Health, Economics, and Health Economics, North Holland, Amsterdam, 246-267.

ZWEIFEL, P. [1982 a]: Ein ökonomisches Modell des Arztverhaltens, Lecture Notes in Economics and Mathematical Systems Nr. 198, Springer-Verlag, Heidelberg.

ZWEIFEL, P. [1982 b] : "Inflation in the health care sector and the demand for insurance: a micro study", in : Feldstein, M. S. and Sheshinski, E. (Eds.), The Arne Ryde Symposium on Social Security, forthcoming in the series "Studies in Public Economics", North Holland, Amsterdam. 